\title{
Determinants of Demand for Private Long-Term Care Insurance (Empirical Evidence from Poland)
}

\author{
Lukasz Jurek $^{1, *(\mathbb{D})}$ and Wioletta Wolańska ${ }^{2}$ \\ 1 Department of Sociology and Social Policy, Wroclaw University of Economics and Business, \\ 53-345 Wroclaw, Poland \\ 2 Department of Forecasts and Economic Analysis, Wroclaw University of Economics and Business, \\ 53-345 Wroclaw, Poland; wioletta.wolanska@ue.wroc.pl \\ * Correspondence: lukasz.jurek@ue.wroc.pl
}

\section{check for} updates

Citation: Jurek, Łukasz, and Wioletta Wolańska. 2021. Determinants of Demand for Private Long-Term Care Insurance (Empirical Evidence from Poland). Risks 9: 27. https:// doi.org/10.3390/risks9010027

Received: 4 December 2020

Accepted: 14 January 2021

Published: 18 January 2021

Publisher's Note: MDPI stays neutral with regard to jurisdictional claims in published maps and institutional affiliations.

Copyright: (c) 2021 by the authors. Licensee MDPI, Basel, Switzerland. This article is an open access article distributed under the terms and conditions of the Creative Commons Attribution (CC BY) license (https:// creativecommons.org/licenses/by/ $4.0 /)$.

\begin{abstract}
The main aim of the article is to evaluate determinants of demand for private long-term care insurance in Poland. Since this type of insurance is not (yet) offered on the market, the demand was examined through a survey in which respondents declared their willingness to purchase it. From the obtained results, it can be concluded that Poles declare a high propensity for private protection in the event of dependence. The vast majority (almost two-thirds) of the respondents were interested in purchasing long-term care insurance, while only one in sixteen respondents showed no such interest. Factors that predominantly determine the willingness to buy are as follows: individual foresight, knowledge about the costs of long-term care, preferences regarding methods of financing care, having children, and the level of education.
\end{abstract}

Keywords: long-term care; dependency; private insurance

\section{Introduction}

The Polish population is one of the fastest aging in the European Union (Giannakouris 2008). In particular, there is a rapidly growing share of very old people (aged 85 years and more) who often cannot perform basic activities of daily living due to natural limitations (reduced physical or mental capacity). At the same time, there are various quickly progressing socio-cultural changes (an increase in women's professional activity, population migration, changes in attitudes and social values) which cause a decrease in the care capacity of families. This is manifested by the fact that family members, who until now have been the main source of care for the elderly, are less and less able and willing to perform these tasks. On the one hand, there is therefore a rapid increase in demand for long-term care, while on the other hand, the supply of informal services is reduced. This naturally forces an increase in the use of formal services that are provided for a fee. It raises a serious economic problem related to the financing of such services.

In European countries, the methods of financing long-term care (LTC) are quite diverse (Costa-Font and Courbage 2011). Generally, expenses are incurred mainly from public funds. In some countries (e.g., the Nordic countries, England, France) there is a method of social provision based on universal access to benefits financed from budget funds. In others (e.g., Germany), there is a social insurance method based on insurance funds, into which there are paid obligatory contributions from which the benefits are financed. Private funds are an important, although most often only complementary, element of LTC financing, thanks to which it is possible to extend the scope or improve the quality of the services offered by the state.

Long-term care insurance (LTCI) is one of the forms of private funding. Its purpose is to increase the ability of individuals to incur potential (future) expenses for long-term care. Unlike health insurance, which covers (primarily) the cost of medical treatment during illness, LTCI protects against costs associated with non-medical care. It redistributes 
the costs of long-term care between people with smaller and larger care needs, thereby pooling risk and reducing individual uncertainty, as well as protecting against catastrophic expenses.

Today there is practically no LTCI market in Poland (Więckowska 2010). Only assistance-type insurance is available, which is usually sold together with banking services. This is only a substitute for classic care insurance, and the possibility of its use by the elderly is extremely limited due to the exclusion of protection in the case of chronic or mental diseases, as well as depression. As a result, one of the most significant financial uncertainties - the risk of long-term care costs-remains insufficiently secured.

Much empirical research has been conducted recently to investigate LTCI demand in different countries, as it was shown by Lambregts and Schut (2019). In Poland, however, this subject still remains relatively poorly recognized. The aim of our study is to identity the potential interest of this product. We will recognize the market potential and determinants of demand for LTCI in Poland.

\section{Demand for LTCI: Theoretical Background}

Prevalence of LTCI differs from country to country, but generally, it has only a marginal importance in financing LTC, therefore it is treated as a "niche" financial product. Usually it covers about $2 \%$ of total LTC spending (OECD 2011). Even in countries where private insurance is widely used (e.g., USA, Japan), this share is relatively small and does not exceed $7 \%$. In some countries, however, private insurance does not work at all and longterm care is financed from other sources.

The differences in the level of LTCI prevalence are mainly due to different organization of social security system. As a rule, private insurance is complementary to social security and has a complementary function to public long-term care financing programs. Interestingly, however, even in those countries where the social function of the state is marginal and boils down only to the last resort or safety net, there also the LTCI market remains small (Scalon 1992; Brown and Finkelstein 2009). This is so even despite implementation of various policy initiatives to increase the uptake of this product, such as tax incentives, public-private partnership plans, tightening eligibility for publicly funded LTC services, and consumer awareness campaigns (McGarry et al. 2016).

Underdevelopment of the LTCI market goes against simple theoretical predictions and is the result of the impact of various factors that together form so-called "LTC insurance puzzle" (Cremer et al. 2012).

In literature, there are many potential explanations for the limited size of the private LTCI market. Some of them are on the demand side and others are on the supply side. As for supply, there are many risks for insurers that substantially reduce the attractiveness of providing LTCI. Three major of those risks are risk of escalating costs, risk of adverse selection, and risk of moral hazard (Kessler 2008). As for demand, in turn, there are many explanations related with both rational non-purchasing factors and behavioral imperfections.

One of the rational non-purchasing factors is high price, that makes LTCI unaffordable. In competitive markets, this price should be equal to actuarially fair premium plus loading costs (Barr 2010). Premium rate results, among others, form the probability of dependency, and this probability, in turn, results directly from age. Too high a price is therefore primarily due to the late decision to purchase insurance, when the risk is too close to certainty. If bought in the period of old age, then taking into account loading costs, which in the case of LTCI are relatively high ${ }^{1}$, it may paradoxically prove that the total sum of contributions is even higher than expected expenditures.

Another factor limiting the demand for LTCI is adverse selection. As a rule, clients on the insurance market have a much better understanding of their health and potential

1 According to Brown and Finkelstein (2007), prices of LTCI are marked up substantially above actuarially fair levels. They estimated that load factor is much larger than, e.g., for standard health insurance, which indicates the existence of supply-side market failures. 
risks (e.g., arising from genetic burden) than insurers. This asymmetry of information causes a situation where for the insurers it is very hard to assume the probability of old-age dependency. Insurance protection is primarily acquired by high-risk individuals (Finkelsteinm and McGarry 2006; Sloan and Norton 1997). Such people who are above average susceptible to the occurrence of a given risk were called by Akerlof (1970) "limons". It is because of them that the risk distribution among insured persons is different (higher) than in the general population.

The phenomenon of negative selection is difficult to eliminate. Although it is possible to verify in detail the applications for an insurance contract, it significantly increases transaction costs. However, if these costs are not incurred, prices will inevitably increase in the long run anyway. This will be due to the fact that, with a certain amount of insurance premium, protection will be more often purchased by "limons", which will increase the expenses (compared to the planned ones) that insurers will incur to pay benefits, which in turn will translate into the need to increase the premium. The price increase will discourage people who are not sure whether they will benefit from it in the future. Eliminating them from the group of customers increases the need to further increase premiums. This cycle leads to a spiral of price increases (Cutler and Zeckhauser 1998).

In addition to the high price, the factor limiting demand for LTCI may also be the unattractive rule of reimbursement (Cremer et al. 2012; He et al. 2020). It is the features of such an insurance as a financial product that are troublesome for customers because insurers frequently do not cover (as it is the case with, e.g., health insurance) the actual costs of benefits, but they pay fixed amounts of money, and this amount depends on the degree of dependence. The long time that elapses between the purchase of insurance and the materialization of risk raises a number of uncertainties, such as the insolvency of the insurer or the maintenance of the real value of the received cash benefits.

Apart from strictly financial issues regarding premiums and benefits, the demand for LTCI is also limited by the availability of various substitutes. One of them is family solidarity. In this case, however, there are a number of doubts and there is no clear empirical confirmation whether the family does indeed opt for crowding out private LTCI. Theoretically, individuals may rely on their spouse and children to be helped in case of dependency. They rationally anticipate receiving care from family, so treat provision of bequests as a substitute for LTCI (Zweifel and Strüwe 1998; Sloan and Norton 1997). In addition, people usually prefer to be cared by family members rather than by unknown caregiver (i.e., in institution). Therefore, as private LTCI reduces costs of formal care and makes it more affordable, the fear of being institutionalized limits the willingness to purchase it. However, if parents are sufficiently altruistic, they will buy LTCI in order to avoid burdening own children. This burden may be treated in terms of both money (in case of formal care) and time (in case of informal care). Therefore, cultural conditions, and more precisely family values and intergenerational relations, are of great importance. From the parents' perspective, the attitude towards formal care is important, e.g., whether benefitting from it is not associated with feelings of shame and failure in life. From the children's perspective, however, it is important to feel obliged to personally engage in caring for their parents. The basis for this involvement is also important, i.e., real motivation for family solidarity. It may be based on pure altruism (dedication), forced altruism (social norms), or reciprocal altruism (bequest) (Cremer et al. 2012).

There are many theoretical speculations about impact of having children on LTCI purchase, but empirical evidence is very limited and gives contradictory results. Courbage and Roudaut (2008) using SHARE data for France found that LTCI is purchased mainly for financial reasons, to preserve bequests and to protect (financially) family members in case of dependency, but also to reduce the burden on potential informal care givers. Opposite results were achieved by Jiménez-Martín et al. (2016). Using SHARE data for Spain, they found that having a children (mainly daughters) discourages LTCI, whereas not having children increases probability of purchasing this product. 
LTCI is being crowded out also by state assistance. Public-funded programs lowers the expected utility of private insurance (Brown and Finkelstein 2008). This applies not only to the actual scope of welfare programs, but also to the expectations on the future scope of these programs (Comas-Herrera et al. 2012). According to Pauly (1990), under state-provided care it is rational not to purchase LTCI, even if it is available at actuarially fair premiums. Moreover, he claims that society is generally poorly informed about the tasks of the welfare state. Citizens mistakenly believe that if they ever need long-term care, it will be financed from public funds. This opinion was confirmed empirically by $\mathrm{T}$. Zhou-Richter et al. (2010). Their study showed that the lack of reliable information on the costs of long-term care and the sources of its financing significantly reduces the demand for LTCI.

In addition to these rational factors that limit the demand for LTCI, a number of other factors can be distinguished that cause people not to make fully rational decisions and refrain from buying insurance even when it would be beneficial for them. Such bounded rationality, as it was called by H. Simon (1972), is related with many psychological factors, such as low self-control (Shefrin and Thaler 1988) and various cognitive biases (Kahneman 2013). Currently, it is a subject of growing interest in economic research (i.e., De Donder and Leroux 2013; Boyer et al. 2019; Schernberg 2019; Klimaviciute 2020).

Bounded rationality in LTCI purchase is also result of lack of risk awareness and financial illiteracy. People usually are not able to assess properly the risk of old-age dependency and potential costs of long-term care (Bacon et al. 1989). They are also unaware of financial consequences of their decisions. According to Jiménez-Martín et al. (2016) being an informal caregiver increases the probability of insurance purchase. It was claimed, that "provision of informal care can reduce the incidence of intertemporal myopia, in the sense that caregivers have a more realistic perception of the risks associated with aging" (p. 173). Lin and Prince (2016), in turn, found that financial literacy notably increases probability of LTCI purchase. Similarly, McGarry et al. (2016) confirmed that numeracy, i.e., the ability to understand and manipulate numeric information, determined LTCI ownership.

\section{Research Goal and Data Acquisition Method}

The main purpose of this article was to diagnose LTCI demand determinants in Poland. Since this type of insurance is not (yet) offered on the market, the demand was examined through a survey in which respondents declared whether they would be interested in purchasing LTCI. It is important to note that we are not talking about real demand, but about potential demand. It is therefore about determining market potential, which is expressed in the interest in purchasing the product. Potential demand may or may not be reflected in reality. Whether the person interested in purchasing will eventually make the purchase depends on numerous factors, such as price, promotion method, or distribution method.

We verified the impact of the following factors on LTCI demand:

1. Material situation: we checked if people who are positively or negatively assessing their level of wealth were more interested in purchasing LTCI. Theoretically, people with low material status should be more eager to secure their future because in their case it would be particularly difficult to pay for care in old age. On the other hand, wealthy people have the greatest opportunities to save for private care, and they can also have a relatively high level of insurance awareness.

2. Possession of offspring: we checked whether the childfree or the parents were more interested in purchasing LTCI. On the one hand, numerous offspring can be a demotivating factor for LTCI purchases, because children can be seen as a natural substitute for old age care; on the other hand, it can be a motivating factor for buying LTCI, as insurance protects against loss of relatives and also protects the parents from becoming a burden for the children in old age.

3. Gender: we checked if men or women were more interested in purchasing LTCI. It may seem that, according to the principle of negative selection, LTCI should be more 
readily acquired by women, because due to the longer life expectancy, they are more burdened with the risk of dependence, and thus higher costs of long-term care. Men not only die sooner, but they are more likely to receive informal care provided by their life partners (wives).

4. Age: we checked if people in early or late adulthood were more interested in purchasing LTCI. According to the idea of care insurance, it is more cost-effective the sooner it is purchased. However, it can be presumed that in the face of budget restrictions and the need to finance other (more urgent) things, the desire to purchase such a product appears only in the period of late adulthood or even early old age.

5. Place of residence: we checked how the place of residence is related to the willingness to purchase LTCI, and whether the inhabitants of cities or small towns and villages showed greater interest in this product. Theoretically, natural forms of care are more developed in villages, based on traditional family roles and neighborly assistance, while in large agglomerations, formal (paid-for) support is more often employed, due to the lower ability and inclination to provide traditional care by relatives.

6. Professional status: we checked whether the fact of having or not having a job was related to the propensity to buy LTCI. Presumably, working people generally show a higher level of resourcefulness than non-working people, and therefore also a higher propensity to protect themselves in the event of various life events, including dependence. On the other hand, the lack of a job should additionally stimulate the person (apart from the issue of budgetary constraints) to secure themselves for the future.

7. Education: we checked whether the level of education was related to the propensity to buy LTCI. We assumed that the higher the level of education, the greater the awareness of various problems and threats, and thus the greater concern for own well-being. It also means greater financial literacy, which provides qualifications for rational household budget management and obtaining funds for the purchase of insurance.

8. Risk awareness: we checked whether the various factors that shape awareness of dependence risk and the costs associated with it had an impact on the propensity to buy LTCI. These factors are as follows: the presence in the immediate environment of the dependent person, experience with formal care (whether the dependent person who is in the environment uses paid care), and knowledge about the costs of longterm care. We assumed that the greater the risk awareness (contact with dependent persons, experience with formal care, and understanding of the costs of this care), the greater the desire to acquire LTCI.

9. Preferences regarding the method of financing long-term care: we checked whether the preferences were related to the willingness to purchase LTCI. We assumed that people advocating individual financing of care are more likely to buy insurance than people advocating other financing methods.

10. Individual foresight: we checked whether the general propensity to protect oneself against different risks affected the desire to purchase LTCI. It can be assumed that people who are generally more prudent about life will also be more willing to protect themselves in the event of dependence.

11. Health status: we checked if people who are positive or negative about their psychophysical condition were more interested in purchasing LTCI. It is likely that the most willing to buy will be the "limons", or people who in their own opinion are the most exposed to the risk of dependence. These people, due to poor health, will be more often forced to use the help of others in the future.

The source material comes from a field study conducted in Poland from 15th February 2016 to 15th March 2016. The aim of the study was to diagnose social attitudes towards the risk of dependence and to identify possible actions taken to protect against this risk. The information was collected using the CATI (computer-assisted telephone interview) method. The territorial scope of the study covered all of Poland, and the subjective scope 
involved people aged 40 to 69 . This age category was considered the most suitable from the perspective of the research goal because of the highest ability and tendency to secure oneself in the event of dependence ${ }^{2}$. It was recognized that at an earlier stage of life people are struggling with other (alternative) economic challenges (e.g., purchase of real estate or raising children). At a later stage of life, in turn, the risk of dependence is so great that the possibility of effective protection against it becomes very limited.

The research sample was 1026 respondents. The selection was carried out in a stratified and random way, so that the sample structure was consistent with the administrative division of the country (voivodship) and with the division into city/village. The sampling frame consisted of Polish residents who were drawn at random from the users of landlines and mobile phones. The maximum measurement error was about $+/-3 \%$ for $p<0.05$. The characteristics of the research sample due to the selected features are presented in Table 1.

Table 1. Distribution of the research sample by selected features.

\begin{tabular}{|c|c|c|c|}
\hline Attribute & Category & $\mathbf{n}$ & $\%$ \\
\hline \multirow{2}{*}{ Gender } & Female & 467 & 45.52 \\
\hline & Male & 559 & 54.48 \\
\hline \multirow{3}{*}{ Age } & $40-49$ & 442 & 43.08 \\
\hline & $50-59$ & 359 & 34.99 \\
\hline & $60-69$ & 225 & 21.93 \\
\hline \multirow{3}{*}{ Place of residence } & Village & 407 & 39.67 \\
\hline & Town & 306 & 29.82 \\
\hline & City & 313 & 30.51 \\
\hline \multirow{3}{*}{ Education } & Primary or incomplete primary & 11 & 1.07 \\
\hline & Secondary, basic vocational, post-secondary & 605 & 58.97 \\
\hline & Higher & 410 & 39.96 \\
\hline \multirow{5}{*}{$\begin{array}{l}\text { Subjective assessment of the } \\
\text { material situation }\end{array}$} & I can afford everything I need and I'm still able to save money & 329 & 32.07 \\
\hline & I can afford everything I need, but I don't save & 74 & 7.21 \\
\hline & I live sparingly, that's why I can afford everything I need & 467 & 45.52 \\
\hline & I can only afford basic expenses & 145 & 14.13 \\
\hline & I can't afford basic expenses & 11 & 1.07 \\
\hline \multirow{5}{*}{ Subjective health assessment } & Very good & 258 & 25.15 \\
\hline & Good & 581 & 56.63 \\
\hline & Average & 160 & 15.59 \\
\hline & $\mathrm{Bad}$ & 22 & 2.14 \\
\hline & Very bad & 5 & 0.49 \\
\hline \multirow{3}{*}{ Children } & None & 101 & 9.84 \\
\hline & One, two & 679 & 66.18 \\
\hline & Three and more & 246 & 23.98 \\
\hline \multirow{2}{*}{ Professional status } & Active & 743 & 72.42 \\
\hline & Inactive & 283 & 27.58 \\
\hline \multirow{6}{*}{ Region } & Central & 209 & 20.37 \\
\hline & Southern & 211 & 20.57 \\
\hline & Eastern & 179 & 17.45 \\
\hline & North-western & 244 & 23.78 \\
\hline & South-western & 27 & 2.63 \\
\hline & Northern & 156 & 15.20 \\
\hline
\end{tabular}

2 LTCI does not have to be purchased only for oneself. It may be purchased also for someone else (for example, by children for their parents) to secure against potential burden. In this research, however, we focused only on self-protection option. 
Table 1. Cont

\begin{tabular}{|c|c|c|c|}
\hline Attribute & Category & $\mathbf{n}$ & $\%$ \\
\hline \multirow{2}{*}{ A person in need of care } & Yes & 671 & 65.40 \\
\hline & No & 355 & 34.60 \\
\hline \multirow{5}{*}{ Tendency to secure own future } & 1 low & 46 & 4.48 \\
\hline & 2 & 171 & 16.67 \\
\hline & 3 & 460 & 44.83 \\
\hline & 4 & 282 & 27.49 \\
\hline & 5 high & 67 & 6.53 \\
\hline \multirow{2}{*}{$\begin{array}{l}\text { Experience with a formal } \\
\text { caregiver }\end{array}$} & There was a formal caregiver & 191 & 18.62 \\
\hline & There was no formal caregiver & 480 & 46.78 \\
\hline \multirow{5}{*}{ Knowledge about LTC costs } & 1 low & 56 & 5.46 \\
\hline & 2 & 301 & 29.34 \\
\hline & 3 & 413 & 40.25 \\
\hline & 4 & 208 & 20.27 \\
\hline & 5 high & 48 & 4.68 \\
\hline \multirow{2}{*}{ Financing preferences } & Individual & 239 & 23.29 \\
\hline & Other & 787 & 76.71 \\
\hline
\end{tabular}

Source: Author's own elaborations.

\section{The Demand for LTCI in Poland in the Light of Empirical Research}

People participating in the study were asked the following question: "In some countries (e.g., France, USA) there is available private care insurance which clients can take out and, if necessary, finance their care from it. If such a service were available in Poland, would you be interested in purchasing it for yourself?". The respondents chose one of five answer options: (1) definitely yes; (2) rather yes; (3) I don't know, I didn't think about it; (4) rather not; or (5) definitely not.

We assumed that each of these answers corresponded to a specific level of interest in purchasing care insurance. People who say "definitely yes" represent the highest (first) level of this interest and can be identified as determined. People who answer "rather yes" represent a lower (second) level of interest and can be identified as positive. People who say "I don't know" represent a third level of interest and may be identified as undecided. People who say "rather not" represent the fourth level of interest and may be described as skeptical. Respondents who say "definitely not" represent the lowest (fifth) level of interest and may be identified as reluctant. The percentage share of individual groups (together with confidence intervals) is presented in Figure 1.

Based on the obtained results, it can be concluded that Poles declare a high propensity to private protection in the event of dependence. The vast majority (almost two-thirds) of the respondents were interested (definitely yes and rather yes) in buying care insurance, while only one in sixteen respondents showed no interest (rather not and definitely not). It is difficult to unequivocally explain the reason for so much interest. Perhaps this is a manifestation of a lack of confidence in the institutions of the welfare state, i.e., a lack of faith that in the future care will be financed from public funds. In this situation, it is natural to look for alternative ways to protect oneself in old age. It is also possible that this is the effect of high risk awareness, which is notoriously aroused by mass media by frequent messages regarding the aging process of the population and the threats it brings to the long-term care system. It cannot be ruled out that this was also influenced by the introductory questions asked during the interview, which made the respondents aware of the importance of the problem and increased their willingness to purchase insurance. 


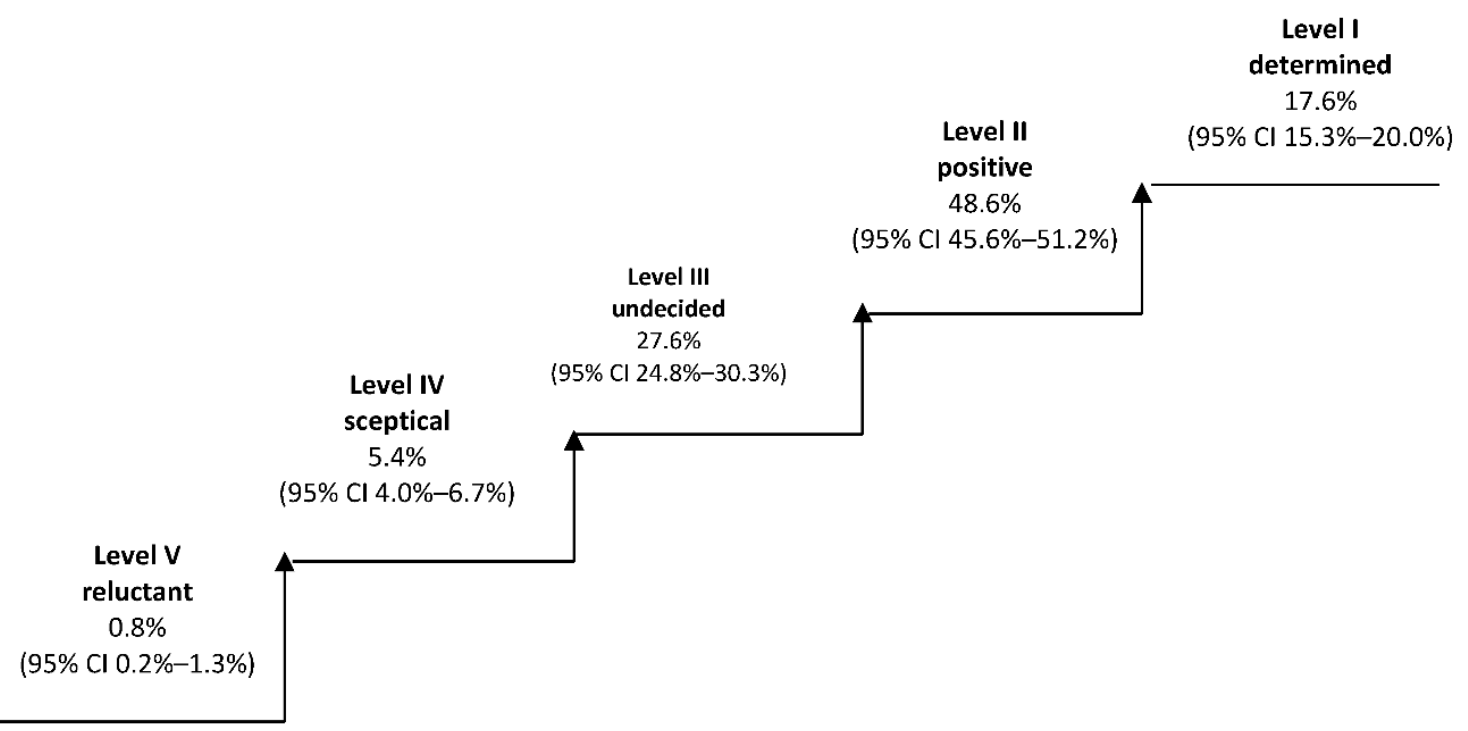

Figure 1. Respondents by level of interest in purchasing long-term care insurance (LTCI) (source: Author's own elaboration).

The willingness to buy insurance was measured on a 5-point scale: "definitely yes"$17.6 \%$, "rather yes" - 48.6\%, "I don't know, I didn't think about it" - 27.6\%, "rather not"— $5.4 \%$, and "definitely not" $-0.8 \%$. The last two categories had low frequencies. Therefore, in order to avoid a large number of proportion of zero frequencies in cross tables, data aggregation was performed to analyze the distribution of respondents' responses depending on selected features. The applied simplification did not interfere with the aim of the study, the group of people interested in purchasing insurance was compared with the others (not interested and having no opinion on this matter).

Table 2 contains distributions of the respondents' opinions regarding interest in purchasing LTCI depending on selected socio-economic features and the value of measures of the relationship between the willingness to purchase insurance and the distinguished features ( $p$-value for chi-square independence test and Cramer's V). Significant ( $p$-value $<0.01)$ differences were found for respondent's place of residence, education, material and health situation, experience with a person requiring care, tendency to secure own future, knowing LTC costs, and preferences for financing long-term care. All statistical analyses were performed using IBM SPSS Statistics computer program. It has been found that gender, age, children, and working status did not cause statistically significant differences in the distribution of the respondents' answers.

The strength of the relationship is the greatest between the interest in purchasing LTCI and the tendency to secure own future (Cramer's V $=0.465$ ) as well as knowledge about LTC costs (Cramer's V $=0.344$ ). The highest percentage of people determined to buy insurance occurred among the population with the highest tendency to secure themselves $(98.5 \%)$, the highest knowledge of LTC costs $(91.7 \%)$, and among those preferring individual financing of long-term care (91.6\%).

Among people who estimated their financial situation as bad, there was the highest percentage of undecided respondents (46\%). It may be assumed that they would like to secure themselves against the risk of dependency but cannot afford it due to the lack of available resources.

Among people with higher education, the level of interest in purchasing LTCI is relatively higher compared to others. Among respondents with basic education, in turn, the percentage of reluctant people is the largest: every third person was not interested in buying LTCI. 
Table 2. Level of interest in purchasing LTCI depending on selected features and measurement of the relationship between them.

\begin{tabular}{|c|c|c|c|c|}
\hline \multirow[b]{2}{*}{ Attribute } & \multirow[b]{2}{*}{ Category } & \multicolumn{2}{|c|}{ Level of Interest in Purchasing LTCI } & \multirow[b]{2}{*}{$\begin{array}{c}\text { Cramer's V } \\
p \text {-Value }\end{array}$} \\
\hline & & $\begin{array}{c}\text { Interested } \\
\text { ("Definitely Yes" } \\
\text { and "Rather Yes") }\end{array}$ & $\begin{array}{c}\text { Others } \\
\text { ("Rather Not", “Definitely } \\
\text { Not" and "I Don't Know") }\end{array}$ & \\
\hline \multirow{2}{*}{ Gender } & Female & 65.5 & 34.5 & 0.015 \\
\hline & Male & 66.9 & 33.1 & 0.640 \\
\hline \multirow{3}{*}{ Age } & $40-49$ & 64.9 & 35.1 & 0.026 \\
\hline & $50-59$ & 67.7 & 32.3 & 0.707 \\
\hline & $60-69$ & 66.7 & 33.3 & \\
\hline \multirow{3}{*}{ Place of residence } & Village & 64.6 & 35.4 & $0.095 * *$ \\
\hline & Town & 61.8 & 38.2 & 0.009 \\
\hline & City & 72.8 & 27.2 & \\
\hline \multirow{3}{*}{ Education } & \multirow{3}{*}{$\begin{array}{c}\text { Primary or incomplete primary } \\
\text { Secondary, basic vocational, } \\
\text { postsecondary } \\
\text { Higher }\end{array}$} & 63.6 & 36.4 & $0.258^{* * *}$ \\
\hline & & 56.2 & 43.8 & $<0.001$ \\
\hline & & 81.2 & 18.8 & \\
\hline \multirow{5}{*}{$\begin{array}{l}\text { Subjective assessment } \\
\text { of the material } \\
\text { situation }\end{array}$} & $\begin{array}{l}\text { I can afford everything I need } \\
\text { and I'm still able to save money }\end{array}$ & 83.6 & 16.4 & $0.291 * * *$ \\
\hline & $\begin{array}{l}\text { I can afford everything I need, } \\
\text { but I don't save }\end{array}$ & 73.0 & 27.0 & $<0.001$ \\
\hline & $\begin{array}{l}\text { I live sparingly, that's why I can } \\
\text { afford everything I need }\end{array}$ & 60.4 & 39.6 & \\
\hline & I can only afford basic expenses & 44.8 & 55.2 & \\
\hline & I can't afford basic expenses & 36.4 & 63.6 & \\
\hline \multirow{5}{*}{$\begin{array}{l}\text { Subjective health } \\
\text { assessment }\end{array}$} & Very good & 40.0 & 60.0 & $0.125^{* *}$ \\
\hline & Good & 72.7 & 27.3 & 0.003 \\
\hline & Average & 60.6 & 39.4 & \\
\hline & Bad & 63.7 & 36.3 & \\
\hline & Very bad & 75.6 & 24.4 & \\
\hline \multirow{3}{*}{ Children } & None & 62.4 & 37.6 & 0.068 \\
\hline & One, two & 67.9 & 32.1 & 0.322 \\
\hline & Three and more & 63.4 & 36.6 & \\
\hline \multirow{2}{*}{ Professional status } & Active & 67.7 & 32.3 & 0.049 \\
\hline & Inactive & 62.5 & 37.5 & 0.119 \\
\hline \multirow{3}{*}{$\begin{array}{l}\text { Experience with a } \\
\text { person requiring care }\end{array}$} & No & 63.1 & 36.9 & 0.0490 .117 \\
\hline & $\begin{array}{l}\text { There was a formal } \\
\text { caregiver }\end{array}$ & 85.3 & 14.7 & $0.193^{* * *}$ \\
\hline & $\begin{array}{l}\text { There was no formal } \\
\text { caregiver }\end{array}$ & 61.0 & 39.0 & $<0.001$ \\
\hline \multirow{5}{*}{$\begin{array}{l}\text { Tendency to secure } \\
\text { own future }\end{array}$} & 1 low & 30.4 & 69.6 & $0.465^{* * *}$ \\
\hline & 2 & 36.8 & 63.2 & $<0.001$ \\
\hline & 3 & 59.8 & 40.2 & \\
\hline & 4 & 92.9 & 7.1 & \\
\hline & 5 high & 98.5 & 1.5 & \\
\hline \multirow{5}{*}{$\begin{array}{l}\text { Knowledge about LTC } \\
\text { costs }\end{array}$} & 1 low & 35.7 & 64.3 & $0.344^{* * *}$ \\
\hline & 2 & 47.5 & 52.5 & $<0.001$ \\
\hline & 3 & 68.5 & 31.5 & \\
\hline & 4 & 91.3 & 8.7 & \\
\hline & 5 high & 91.7 & 8.3 & \\
\hline \multirow{2}{*}{ Financing preferences } & Individual & 91.6 & 8.4 & $0.375^{* * *}$ \\
\hline & Other & 58.6 & 41.4 & $<0.001$ \\
\hline
\end{tabular}


As was expected, respondents positively assessing their financial situation were more interested in buying LTCI than respondents assessing this situation as negative.

Among respondents having dependent person in their environment, those cooperating with formal caregivers were much more likely to be interested in purchasing LTCI than those who do not cooperate with formal providers.

\section{Determinants of LTCI Demand in Poland}

People participating in the study were divided into two groups, where the division criterion was their attitude towards purchasing LTCI. The first group consisted of people interested in buying such insurance product, i.e., "determined" and "positive" individuals. In total, there were 680 respondents in this group. The other group consisted of all others, i.e., "undecided", "skeptical", and "reluctant" respondents. In this second group, there were a total of 346 respondents. A binomial logistic regression model was used to evaluate the impact of selected features on interest in purchasing LTCI. The explanatory variable $Y$ was the binary variable, propensity to buy:

$$
\mathrm{Y}=\left\{\begin{array}{c}
1-\text { willingness to purchase LTCI } \\
0-\text { reluctance to purchase LTCI or lack of opinion }
\end{array}\right.
$$

Potential explanatory variables were taken into the model as shown in Table 3 based on the previously presented research hypotheses, the distribution of answers to the question about the interest in purchasing LTCI, and also the analysis of the number in the multidivision tables.

Table 3. Explanatory variables in the model explaining the propensity to purchase LTCI.

\begin{tabular}{|c|c|}
\hline Gender & categorical variable with a value of 1 for men and 0 for women \\
\hline Age & $\begin{array}{l}\text { ordinal 3-state variable, for which two } 0-1 \text { variables were introduced, taking people aged } \\
40-49 \text { as reference variable }\end{array}$ \\
\hline Place of residence & $\begin{array}{l}\text { ordinal 3-state variable, for which two } 0-1 \text { variables were introduced, taking cities as the } \\
\text { reference variable }\end{array}$ \\
\hline Education & $\begin{array}{l}\text { ordinal 2-state variable with the value } 1 \text { for higher education and } 0 \text { for lower than higher } \\
\text { education }\end{array}$ \\
\hline $\begin{array}{l}\text { Subjective assessment of the } \\
\text { material situation }\end{array}$ & $\begin{array}{l}\text { ordinal 5-state variable, for which four 0-1 variables were introduced, taking "I can't afford } \\
\text { basic expenses" as reference variable }\end{array}$ \\
\hline Subjective health assessment & $\begin{array}{l}\text { ordinal 5-state variable, for which four } 0-1 \text { variables were introduced, taking "very bad" as } \\
\text { reference variable }\end{array}$ \\
\hline Children & nominal variable with a value of 0 for people with children and 1 for people without children \\
\hline Professional status & nominal variable with a value of 1 for working people and 0 for non-working people \\
\hline Presence of dependent person & $\begin{array}{l}\text { nominal variable with a value of } 1 \text { for people who have someone in their environment who is } \\
\text { dependent and requires care, and } 0 \text { for people who do not have someone like that in their } \\
\text { environment }\end{array}$ \\
\hline Experience with formal care & $\begin{array}{l}\text { nominal variable with a value of } 1 \text { if the formal caregiver participated in the care process for } \\
\text { the dependent person and } 0 \text { if the services of a formal caregiver were not used }\end{array}$ \\
\hline Individual foresight & $\begin{array}{l}\text { ordinal 5-state variable, for which four } 0-1 \text { variables were introduced, taking " } 1 \text { low" as } \\
\text { reference variable }\end{array}$ \\
\hline Knowledge of LTC costs & $\begin{array}{l}\text { ordinal } 5 \text {-state variable, for which four } 0-1 \text { variables were introduced, taking " } 1 \text { low" as } \\
\text { reference variable }\end{array}$ \\
\hline Preference for LTC financing & $\begin{array}{l}\text { nominal variable with a value of } 1 \text { if the respondent believes that everyone should bear the } \\
\text { costs of their own formal care and } 0 \text { for other opinions }\end{array}$ \\
\hline
\end{tabular}


Regression coefficients for variables: gender, age, place of residence, health status, material situation assessment, professional status, presence of a dependent person requiring long-term care, knowledge of long-term care costs (category " 2 "), tendency to secure own future (category " 2 "), and experience with a formal caregiver proved to be statistically insignificant (for $p=0.05$ ), which is equivalent to the fact that the odds ratios for these variables did not differ significantly from 1 . This means that these variables did not significantly affect the preferences regarding the purchase LTCI and were excluded from the set of predictors. Table 4 presents the results of the estimation of the re-estimated model with a reduced number of explanatory variables.

Table 4. Estimation results of the logit model of the propensity to purchase LTCI in Poland.

\begin{tabular}{cccc}
\hline Variable & Parameter B & $p$-Value & Odds Ratio Exp(B) \\
\hline Constant & -0.990 & 0.0000 & \\
\hline Individual foresight & & & \\
1 low-ref. & & & \\
3 & $0.608^{* * *}$ & 0.0008 & 1.838 \\
4 & $2.227^{* * *}$ & 0.0000 & 9.272 \\
5 high & $3.599^{* * *}$ & 0.0005 & 36.555 \\
\hline Knowledge about the cost of care & & & \\
1 low-ref & & & 1.910 \\
3 & $0.647^{* * *}$ & 0.0001 & 4.404 \\
4 & $1.482^{* * *}$ & 0.0000 & 3.857 \\
5 high & $1.350^{* *}$ & 0.0229 & 2.448 \\
Education & $0.895^{* *}$ & 0.0011 & 1.920 \\
Children & $0.652^{* * *}$ & 0.0002 & 0.533 \\
\hline
\end{tabular}

Goodness of fit statistics:

Likelihood ratio $(9)=329.8, p<0.001$

Hosmer Lemeshow $=3.5202, p=0.7413$

$\%$ correct predictions $=74.2 \%$

Nagelkerke's $\mathrm{R}^{2}=0.381$

Note: Significant at ${ }^{*} p<0.05,{ }^{* *} p<0.01,{ }^{* * *} p<0.001$. Source: Author's own elaboration.

Individual foresight had the greatest impact on the willingness to purchase $\mathrm{LTCI}^{3}$. People declaring themselves as extremely prudent are thirty-six times more likely to buy such insurance than those not considering themselves as prudent at all. Therefore, the dominant role is played by the mentality, and more precisely by the psychologically conditioned tendency to self-protection in economic terms.

The second most important factor affecting respondents' preferences was knowledge about the costs of long-term care. The chance of buying LTCI among people with a high level of knowledge was over four times higher than among people without such knowledge. Therefore, risk awareness plays a crucial role in affecting propensity of LTCI use. People aware of economic consequences of dependence, and more precisely of financial costs (care services, housing re-arrangements etc.), as well as non-financial costs (opportunity costs) are more willing to make a purchase.

Financing of long-term care services is still an unregulated issue in Poland. Currently, an extensive public debate is taking place on managing the risk of dependency. There is, however, no general agreement as to whether LTC should be financed from private (out-of pocket payments, LTCI) or rather public funds (social insurance or budgetary resources). The society is strongly divided in this respect (Wolańska and Jurek 2018). It turns out that preferences on the method of financing LTC are strongly associated with the willingness to

3 The provided interpretations relate to the included set of explanatory variables of the model and the assumption of ceteris paribus. This means that we compared people who have identical values of explanatory variables except for the one at which the parameter is interpreted. 
purchase LTCI. Among people thinking that everyone should pay for care by their own, the chance of being interested in purchasing LTCI was two and a half times higher than among people thinking that care should be financed from other sources.

Another factor that affects the willingness to purchase LTCI is the level of education. The chance of buying insurance by people with higher education was twice as high compared to people with secondary and primary education. It may suggest that a university degree gives skills and knowledge to better risk assessment and more effective self-protection.

Regarding having children, the chance for being interested in purchasing LTCI is lower (by half) among childless people. This suggests that the willingness to buy insurance is affected more by bequest motive and reluctance of being a burden for the children, rather than by the fear of not being able to finance own care. People without children may spend their assets to pay for LTC, and if it is not enough, social care may be regarded as a last resort or a safety net. In this case, availability of public assistance demotivates self-protection. People having children are, in turn, much more motivated to care for own financial security. First of all, they are usually reluctant to spend assets that are expected (by both parents and children) to be transferred descendants. Moreover, in case of dependency, they become a burden (in economic terms) for their own children, not for an anonymous institution. The offspring are morally obligated either to provide care by themselves (opportunity costs) or to co-finance care provided by formal caregiver (financial costs).

Table 5 shows the values of Cramer's V coefficients to assess the relationship between the explanatory variables included in the model. It is already known from earlier findings that the most important factor determining the willingness to purchase LTCI was individual foresight, which in turn was highly correlated with, among others, the material situation. This explains the lack of significance of this particular variable. The second most important factor, knowledge about the LTC costs, was strongly correlated with experience with a formal caregiver, that, in turn, was statistically insignificant. This may suggest that familiarity with formal care has an indirect impact, even though it is not included in the model. However, taking into account the LTC financing method, i.e., the third most important factor, people preferring individual financing also positively assessed their financial situation, which again shows the indirect impact of the financial situation on the willingness to purchase LTCI, despite the statistical insignificance of this particular variable. Moreover, another factor, education, was also strongly correlated with the material situation. Higher education creates objective opportunities for achieving higher income. 
Table 5. The Cramer's V coefficients correlation matrix for the selected variables.

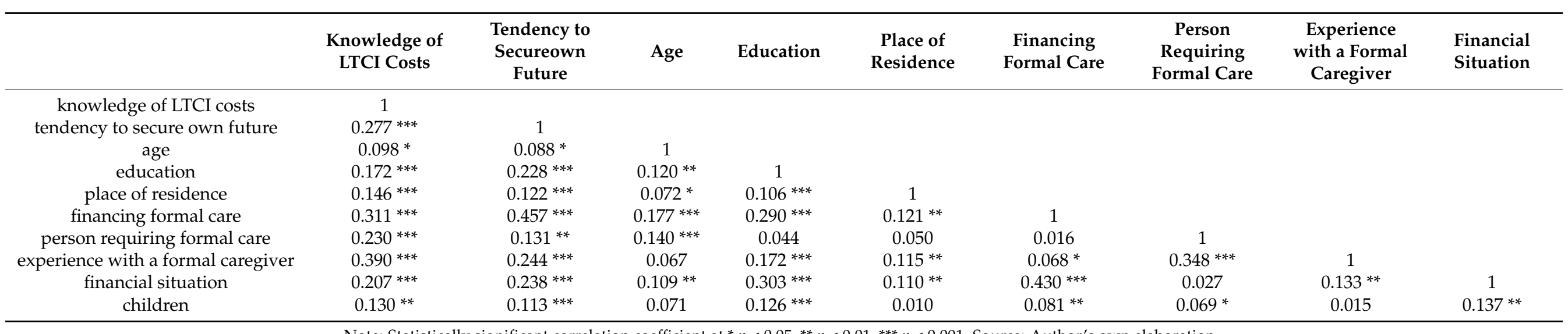

Note: Statistically significant correlation coefficient at ${ }^{*} p<0.05,{ }^{* *} p<0.01,{ }^{* * *} p<0.001$. Source: Author's own elaboration. 


\section{Discussion}

Despite the fact that LTCI is not yet offered in Poland, based on the obtained results, it can be assumed that this product has a large market potential. Over $66 \%$ of respondents declared interest ("definitely yes" or "rather yes") in its purchase.

We managed to confirm the impact of the following factors on the willingness to purchase LTCI: individual foresight, knowledge about the LTC costs, preferences on the methods of LTC financing, having children, and education level. In turn, the impact of the following factors has not been confirmed: material situation, gender, age, place of residence, experience with formal care, professional status, and health status. However, some of these unconfirmed factors are associated with others that are confirmed, which may suggest indirect influence on the willingness to purchase LTCI. Factors creating broadly understood risk awareness can be a good example: experience with formal care, that was not significant in the model, obviously increases the knowledge about LTC costs, which, in turn, has a significant impact on the propensity of LTCI usage.

According to the obtained information, it is possible to create a profile of a potential Polish LTCI purchaser. It is a person who is primarily characterized by high individual foresight, good insight into LTC costs, and a high propensity to self-finance their own commitments. There is a higher probability of interest in insurance among people with higher education and having children. In addition, all these features were strongly associated with the material situation, i.e., people positively assessing their standard of living at the same time were characterized by higher individual foresight, had higher knowledge about LTC costs, preferred an individual method of financing care, and were better educated.

An important limitation of the obtained results is the qualitative nature of the factors determining the willingness to purchase LTCI. This qualitative nature makes it difficult to describe and measure the features of potential customers. Therefore, practical applications are quite limited. Undoubtedly, for insurance companies it would be easier to track down a customer based on their socio-demographic characteristics. It appears, however, that motives of human behavior are determined by more complex factors.

The obtained results also possess a serious interpretation limitation, namely, the study was largely based on the opinions and feelings of respondents. They concerned in particular individual foresight, knowledge about LTC costs, and material situation. The problem is that the subjective assessments of respondents in this regard can be fundamentally different from the actual state. Therefore, it is difficult to draw clear conclusions. Although the research goal was achieved, space for further scientific activities appeared. In order to recognize LTCI market potential, further research needs to be conducted using objectively measured variables.

Author Contributions: Both authors (Ł.J. and W.W.) participated equally. All authors have read and agreed to the published version of the manuscript.

Funding: This research received no external funding.

Institutional Review Board Statement: Not applicable.

Informed Consent Statement: Not applicable.

Data Availability Statement: Not applicable.

Conflicts of Interest: The authors declare no conflict of interest.

\section{References}

Akerlof, George A. 1970. The Market for "Lemons": Quality Uncertainty and the Market Mechanism. The Quarterly Journal of Economics 3: $175-88$. [CrossRef]

Bacon, W. Peter, Lawrence J. Gitman, Khurshid Ahmad, and M. Fall Ainina. 1989. Long-term catastrophic care: A financial planning perspective. Journal of Risk and Insurance 1: 146-54. [CrossRef]

Barr, Nicholas. 2010. Long-term care: A suitable case for social insurance. Social Policy \& Administration 44: 359-74.

Boyer, Martin, Philippe De Donder, Claude Fluet, Marie-Louise Leroux, and Pierre-Carl Michaud. 2019. Long-term care risk misperceptions. The Geneva Papers on Risk and Insurance-Issues and Practice 44: 183-215. [CrossRef] 
Brown, R. Jeffrey, and Amy Finkelstein. 2007. Why is the market for long-term care insurance so small? Journal of Public Economics 91: 1967-91. [CrossRef]

Brown, R. Jeffrey, and Amy Finkelstein. 2008. The Interaction of public and private insurance: Medicaid and the long-term care insurance market. American Economic Review 98: 1083-102. [CrossRef]

Brown, R. Jeffrey, and Amy Finkelstein. 2009. The private market for long-term care insurance in the United States: A review of the evidence. Journal of Risk Insurance 76: 5-29. [CrossRef]

Comas-Herrera, Adelina, Rebeca Butterfield, Jose-Luis Fernandez, Raphael Wittenberg, and Joshua M. Wiener. 2012. Barriers and Opportunities for Private Long-Term Care Insurance in England: What Can We Learn from other Countries. PSSRU Discussion Paper, nr 2780. London: Personal Social Services Research Unit, London School of Economics.

Costa-Font, Joan, and Christophe Courbage. 2011. Financing Long-Term Care in Europe. Houndmills: Palgrave Macmilla.

Courbage, Christophe, and Nolwenn Roudaut. 2008. Empirical evidence on long-term care insurance purchase in France. The Geneva Papers on Risk and Insurances-Issues and Practice 4: 645-58. [CrossRef]

Cremer, Helmuth, Pierre Pestieau, and Gregory Ponthiere. 2012. The economics of long-term care: A survey. Nordic Economic Policy Review 2: 107-48.

Cutler, David, and Richard Zeckhauser. 1998. Adverse selection in health insurance. Forum for Health Economics E Policy 1: 1-33.

De Donder, Philippe, and Marie-Louise Leroux. 2013. Behavioral Biases and Long-Term Care Insurance: A Political Economy Approach. The BE Journal of Economic Analysis E Policy 14: 551-75.

Finkelsteinm, Amy, and Kathleen McGarry. 2006. Multiple dimensions of private information: Evidence from the long-term care insurance market. American Economic Review 4: 938-58. [CrossRef] [PubMed]

Giannakouris, Konstantinos. 2008. Ageing characterises the demographic perspectives of the European societies. Eurostat Statistics in Focus 72: 2008.

He, Alex Jingwei, Jiwei Qian, Wai-sum Chan, and Kee-lee Chou. 2020. Preferences for private long-term care insurance products in a super-ageing society: A discrete choice experiment in Hong-Kong. Social Science E Medicine 270: 113632.

Jiménez-Martín, Sergi, José M. Labeaga-Azcona, and Cristina Vilaplana-Prieto. 2016. Interactions between Private Health and Long-term Care Insurance and the Effects of the Crisis: Evidence for Spain. Health Economics 25: 159-79. [CrossRef]

Kahneman, Daniel. 2013. Thinking, Fast and Slow. New York: Farrar, Straus and Giroux.

Kessler, Denis. 2008. The long-term care insurance market. The Geneva Papers on Risk and Insurances-Issues and Practice 1: 33-40. [CrossRef]

Klimaviciute, Jusitina. 2020. Long-term care and myopic couples. International Tax and Public Finance 27: 77-102. [CrossRef]

Lambregts, Timo R., and Frederik T. Schut. 2019. A Systematic Review of the Reasons for Low Uptake of Long-Term Care Insurance and Life Annuities: Could Integrated Products Counter Them? Netspar Survey Paper no. 55, Network for Studies on Pensions, Aging and Retirement. Available online: https:/ / www.netspar.nl/assets/uploads/P20190822_SUR55_Lambregts.pdf (accessed on 16 January 2021).

Lin, Hazhen, and Jeffrey T. Prince. 2016. Determinants of Private Long-Term Care Insurance Purchase in Response to the Partnership Program. Health Services Research 51: 687-703. [CrossRef]

McGarry, Brian E., Helena Temkin-Greener, Benjamin P. Chapman, David C. Grabowski, and Yue Li. 2016. The Impact of Consumer Numeracy on the Purchase of Long-Term Care Insurance. Health Services Research 51: 1612-31. [CrossRef]

OECD. 2011. Help Wanted? Providing and Paying for Long-Term Care. Paris: OECD Publishing.

Pauly, Mark. 1990. The Rational Non-Purchase of Long-Term Care Insurance. Journal of Political Economy 98: 153-68. [CrossRef]

Scalon, William J. 1992. Possible Reforms for Financing Long-Term Care. The Journal of Economic Perspectives 3: 43-58. [CrossRef] [PubMed]

Schernberg, Helene. 2019. Long-Term Care Insurance Purchase under Time-Inconsistent Risk Attitudes. Available online: https: / / ssrn.com/abstract=3418316 (accessed on 16 January 2021).

Shefrin, Hersh, and Richard Thaler. 1988. The behavioral live-cycle hypothesis. Economic Inquiry 26: 609-43. [CrossRef]

Simon, Herbert A. 1972. Theories of bounded rationality. Decisions and Organization 1: 161-76.

Sloan, Frank A., and Edward C. Norton. 1997. Adverse Selection, Bequests, Crowding Out, and Private Demand for Insurance: Evidence from the Long-Term Care Insurance Market. Journal of Risk and Uncertainty 15: 201-19. [CrossRef]

Więckowska, Barabara. 2010. Ubezpieczenie w zarządzaniu ryzykiem niedołęstwa starczego. In Społeczne Aspekty Rynku Ubezpieczeniowego. Edited by Tadeusz Szumlicz. Warszawa: Oficyna Wydawnicza SGH, pp. 209-20.

Wolańska, Wioletta, and Łukasz Jurek. 2018. Preferencje wobec sposobu finansowania opieki długoterminowej w Polsce. Ubezpieczenia Spoteczne. Teoria i Praktyka 3: 97-113.

Zhou-Richter, Tian, Mark J. Browne, and Helmut Gründl. 2010. Don't they care? Or, are they just unaware? Risk perception and the demand for long-term care insurance. The Journal of Risk and Insurance 4: 715-47. [CrossRef]

Zweifel, Peter, and Wolfram Strüwe. 1998. Long-Term Care Insurance in a Two-Generation Model. Journal of Risk and Insurance 65: 13-32. [CrossRef] 